\title{
Synergistic Effect of TGF-ß1 And BMP-7 on Chondrogenesis and Extracellular Matrix Synthesis: An In Vitro Study
}

\author{
Alper Gokce ${ }^{*}, 1$, Ibrahim Yilmaz ${ }^{2}$, Rifat Bircan ${ }^{3}$, Murat Tonbul ${ }^{1}$, Nevzat Selim Gokay ${ }^{4}$ and \\ Cigdem Gokce 5
}

\author{
${ }^{I}$ Department of Orthopaedics and Traumatology, Namik Kemal University, School of Medicine, Tekirdag, Turkey \\ ${ }^{2}$ Tekirdag State Hospital, Turkish Republic Ministry of Health, Tekirdag, Turkey \\ ${ }^{3}$ Department of Molecular Biology and Genetics, Faculty of Science, Namik Kemal University, Tekirdag, Turkey \\ ${ }^{4}$ Department of Orthopaedics and Traumatology, Namik Kemal University, School of Medicine, Tekirdag, Turkey \\ ${ }^{5}$ Community Health Center of Uskudar District, Turkish Republic Ministry of Health, Istanbul, Turkey
}

\begin{abstract}
Introduction: The purpose of the present study seeks to determine the signal timing of BMP-7 and TGF- $\beta 1$ from a novel chitosan based hydrogel system that may affect chondrocyte proliferation resulting in the presence of a synergism seen conspicuously in consecutive controlled delivery.

Methods: Four groups of cultured chondrocytes were seeded on a novel designed chitosan based hydrogel. The hydrogel was left empty (control) in one group and loaded with BMP-7, TGF- $\beta 1$ and their combination in the other groups, respectively. Hydrogel structure was analyzed with scanning electron microscope. The release kinetics of Growth Factors (GFs) was determined with ELISA. Chondrocyte viability and toxicity after being tested with MTS and collagen type II synthesis, were quantified with western blotting. Canonical regression analysis was used for measuring statistical evaluation.

Results: Chitosan based hydrogel allowed controlled release of GFs in different time intervals for BMP-7 and TGF- $\beta 1$. Double peak concentration gradient was found to be present in the group loaded with both GFs. In this group, substantially higher chondrocyte growth and collagen synthesis were also detected.

Conclusions: We concluded that, chitosan based hydrogel systems may be adjusted to release GFs consecutively during biodegradation at the layers of surface, which may increase the cell number and enhance collagen type II synthesis.
\end{abstract}

Keywords: Chondrocyte culture, hydrogel, chitosan, controlled release, BMP-7, TGF- $\beta 1$, cartilage.

\section{INTRODUCTION}

Cartilage tissue possesses limited capacity to self repair due to low mitotic activity of chondrocytes and limited synthesis of extracellular matrix $[1,2]$. Tissue engineering has been introduced as a promising research field to replace the defected area by seeding the in vitro grown chondral cells [3]. The chondrocytes are usually seeded in the scaffolds, produced from several synthetic or natural materials. They form clinically functional ex vivo tissue, exhibiting histological and biomechanical properties identical to native cartilage $[4,5]$. However, in recent studies, the developed neocartilage has still been found in fibrous nature not fulfilling the mechanical properties of their hyaline counterpart considering the extracellular matrix composition $[6,7]$.

Previous studies showed that several growth factors (GFs), such as transforming growth factor beta 1 (TGF- $\beta 1$ )

\footnotetext{
*Address correspondence to this author at the TC Namik Kemal Universitesi Arastirma ve Uygulama Hastanesi 100. Yil Mahallesi Tunca Caddesi, Tekirdag 59030, Turkey; Tel: +902822505000;

Fax:+902822509950; E-mail: a.gokce@yahoo.com
}

and bone morphogenic protein 7 (BMP-7) can promote chondrocyte proliferation and extracellular matrix (ECM) synthesis in vitro and in vivo [3, 8]. However, the short halflifes, relatively large molecular size, slow tissue penetration, and potential toxicity at the systemic level have hindered many applications of these bioactive compounds [9].

Incorporation of GFs into polymeric biomaterials, like hydrogels, for maintaining their stability, may enhance the efficacy of growth factors in vitro and in vivo [10].

Chitosan(CS) has been used as a scaffolding material in articular cartilage engineering $[11,12]$, due to its structural similarity with various glycoseaminoglycans naturally present in the ECM of cartilage and has also been used as a base of different controlled release preperations. The delivery of TGF-B1 in a controlled fashion from CS-based scaffolds has marked an increase in biosynthetic ability of chondrocytes $[13,14]$. The regenerative effect of BMP-7 was also investigated by Mattioli-Belmonte et al. in repair induction of femoral articular cartilage lesion in rabbit [15]. Studies have reported that hydrogel systems are embedded with combination of growth factors, but interaction of the signaling activity of the GFs in terms of synergism has not been an issue to be investigated much. 
The purpose of the present study is to test the stimulating efficacy of BMP-7, TGF- $\beta 1$ and their synergistic action on chondrocytes to promote cartilage repair. A combined release pattern consisted of initially BMP-7 followed by TGF- $\beta 1$. For that purpose, TGF- $\beta 1$ loaded hydrogels were coated with BMP7 loaded hydrogels, for delaying the release of TGF- $\beta 1$. BMP-7 and TGF- $\beta 1$ were intended to be released sequentially from chitosan based scaffold in a controlled way. This may aid rhe synergistic effect on chondrocytes to form a better ex-vivo tissue.

\section{MATERIALS AND METHODOLOGY}

\section{Isolation and Culture of Human Chondrocytes}

Cartilage tissue was obtained from the leftover pieces of a total knee replacement surgery of a 55 year old female suffering from symptomatic gonarthrosis. An informed consent was approved and signed by the patient as a volenteer for donating the osteochondral tissue remnants to be used in a cell culture study. The study was honoured with an approval by the local ethics committee. Full thickness pieces of articular cartilage were removed aseptically from subchondral bone with a scalpel and cut into small pieces. The harvested tissue was sent to the laboratory within RPMI 1640 solution (Sigma-Aldrich $\mathrm{GmbH}$, Germany) following the standard transfer instructions within 10 minutes. The chondral parts were freed from the osseous tissue, pinched into small pieces of $1-2 \mathrm{~cm}$ in laminar air-flow cabinette (NUVE / NF-800 R, Akyurt, 06750 Ankara, Turkey) and then washed 3 times with $0.09 \mathrm{M} \mathrm{NaCl}$ solution. The chondral material was treated with collagenase type II (1 mg/ $\mathrm{mL}$; Invitrogen Corporation, USA) and incubated in $37^{\circ} \mathrm{C}$ for 24 hours. After centrifugation for $10 \mathrm{~min}$ at $1200 \mathrm{rpm}$, the supernatant was discarded. The pellet was resuspended in freshly prepared RPMI $1640 \quad 1 \%$ streptomycine and penicillin and 10\% FBS (Sigma Chemical St. Louis, USA). The cells were then transferred to T-25 flasks and cultured throughout 4 weeks period in $\mathrm{CO} 2$ incubator (NUVE /Akyurt, 06750 Ankara, Turkey). The cell growth was determined by MTS Cell Titer 96 Aqueous one solution cell proliferation assay (Promega, USA). Briefly, MTS/PMS reagent $(100 \mathrm{ml})$ was added to each well of the 24 -well plate and incubated for $135 \mathrm{~min}$ at $37^{\circ} \mathrm{C}$ in a $\mathrm{CO} 2$ incubator [15]. The absorbances at $490 \mathrm{~nm}$ (OD 490) were calculated to find the quantity of formazan product being directly proportional to the number of alive cells present.

\section{Preparation of Chitosan Hydrogels}

Four different types of hydrogels from $2 \%$ polycationic biopolimer chitosan (produced from 85-90\% deacylated Chitine (C12H24N209) (poli-[b-(1,4)-2-amino-2-deoxy-bD-glucopyranose]) (Sigma-Aldrich, Germany) were prepared under the laminar flow cabinette (NUVE /Akyurt, 06750 Ankara, Turkey). Sieved chitosan microparticules were mixed with ethanol and bidistilated water $(1: 1 \mathrm{v} / \mathrm{v})$ in magnetic shaker (Wisestir-wisd MSH-20A, Korea) for 5 minutes. PVA solution (\%9, Polyvinyl alcohol; SigmaAldrich Chemie $\mathrm{GmbH}$, Steinheim, Germany) was imbued with chitosan molecules through the addition of chitosan containing water-ethanol mixture. Due to low hydrophylic capacity of PVA a physical net was constituted suspending and homogenizing both its functional hydroxyl-groups and borax (di-sodium tetraborate decahydrate (Merck, Germany), previously in proportion of $1: 3 / 1: 1(\mathrm{w} / \mathrm{v})$. BMP-7 $(22,7$ $\mathrm{ng} / \mathrm{ml})$ and TGF- $\beta 1 \quad(10 \mathrm{ng} / \mathrm{ml})$ were impregnated in produced hydrogel. The material was divided into two different dishes for loading BMP-7 and TGF- $\beta 1$ separetely. Further, an empty and a combined GF loaded two other hydrogels were also prepared.

\section{Characterization of Chitosan Hydrogel with Scanning Electron Microscope (SEM)}

PVA-borax based hydrogel surface characteristic features, pore diameter measurement and matrix structure were investigated with SEM. The pore distirubution and average of diameters of PVA-borax based chitosan hydrogel were investigated with "Scion Image" software. For SEM analysis on the first, 7 th, 14th and 21 st day, one more sample for each group was prepared and the contents of the well were fixed with cacodylate buffer (Sodium Cacodylate Buffer $\mathrm{pH}=6, \quad 5 ; 50 \mathrm{mM}$-isopropanol $15 \%$ solution; Biochemika, Sigma Aldrich).

\section{Seeding of Cells on Chitosan Hydrogels}

Chitosan hydrogel with constant thickness of one and half milimeter was dried in an incubator for 3 hours allocating to each well of 24 well-plate. After achieving adequate confluent with culturing of chondrocytes, cells were picked up from flasks using trypsinisation. In the presence of dilutional solution of trypan blue $(0,4 \%)$, live/dead cell ratios $\left(10^{5}\right.$ cells; $75-80 \%$ of the confluent $)$ were calculated after counting the cells with the help of hemacytometer. Chondrocytes were divided and added to each well containing empty BMP-7 and TGF- $\beta 1$ or combined BMP-7 and TGF- $\beta 1$ loaded controlled release hydrogels respectively (Fig. 1). All hydrogels loaded with GFs and those with unloaded forms (control matrices) were kept in 5\% CO2 incubator for 21 days. On every second day during the experiment period of 21 days, culture media was changed in the same time zone of the day. According to manufacturer's instructions, culture media was enriched with the addition of predefined $5 \mathrm{ml}$ solution of ITS premix I (insulin $5 \mu \mathrm{g}$, human transferin $5 \mu \mathrm{g}$ and sodium selenite 5 ng/ml miture; ITS premix I 1884, Sigma Saint Louis, Missouri, USA).

While changing culture media on the experiment days of $1,3,5,7,9,11,13,15,17,19$ and 21, 500 microliters of supernatant were taken to Eppendorf tubes with commercially available kits for quantifying at microplate reader of enzyme-linked immunosorbent assay (ELISA). Initialy loaded GF amount and released amount of GFs into culture medium were recorded.

\section{Release Kinetics of GFs}

Controlled release kinetics of GFs from hydrogels was detected through determination of released portions with ELISA microplate reader (Shenzhen Mindray MR-96A mikroplate reader, 518057 P.R. China). Absorbance alterations were measured during the release of GFs and absorbance/time graphs were drawn.

\section{MTS Cells Proliferation ELISA Assay}

For MTS measurement, Dulbecco's modified Eagle's Medium (DMEM; 1000 mg glucose/L, Sigma Chemical St. Louis, USA) was used instead of Megacell RPMI-1640 due 


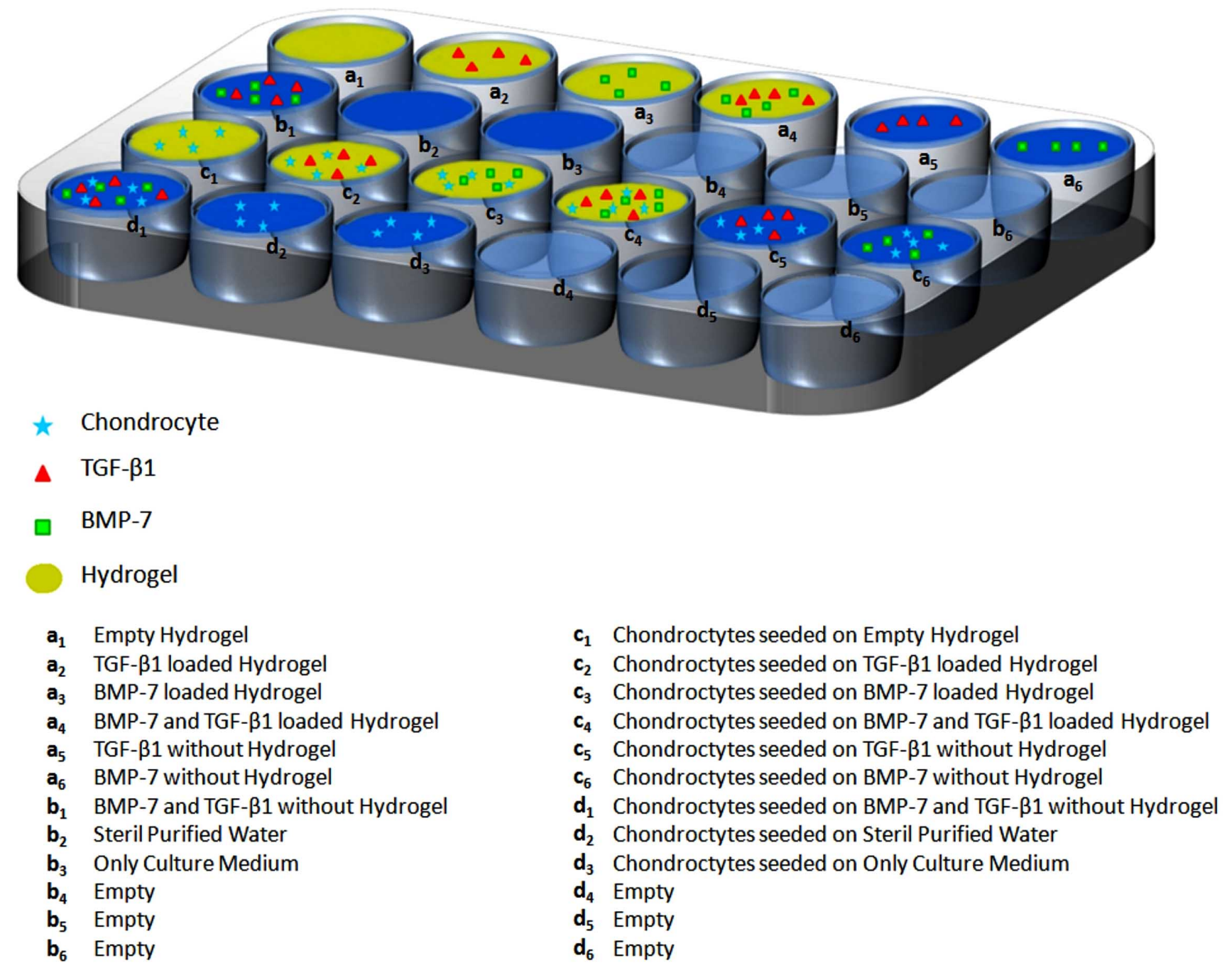

Fig. (1). Study Design; Chondrocytes were added to each well containing empty, BMP-7, TGF- $\beta 1$ or combined BMP-7 and TGF- $\beta 1$ loaded controlled release hydrogels.

to integredients. Under dark room conditions, a solution of MTS (100 ml MTS solution+ $5 \mathrm{ml}$ PMS solution; MTS formazan CellTiter 96 AQueous Non- Radioactive Cell Proliferation Assay) was prepared with a dilution ratio of 1/6 $(\mathrm{v} / \mathrm{v})$. For each study and controll groups cell samples bearing whole content of a well were set part on the $1 \mathrm{st}, 7 \mathrm{th}$, 14 th and 21 st days for spectral photometris examination at $490 \mathrm{~nm}$ (UV Mini 1240-UV-V15 spectrophotometers, Shimadzu, Kyoto, Japan).

\section{Quantification of Collagene Types in Confluents with Western Blot}

The process of determination and detection of collagene types was performed with commercial specific antibodies and I-blot technique according to the manufacturer instructions (Invitrogen Corp. Carlsbad, California). Chondrocytes were collected with scraping from culture wells and washed twice with cold PBS. Collected cell pellet was lysed in cell extraction buffer for 30 minutes, on ice, with vortexing at 10 minute intervals. Commercial kits of collagene type I antibody (Novus Biological NB600-408), collagene type II antibody (Novus Biological AF-5710) and collagene type III Antibody (Novus Biological COL3A1, NBP1-05119) were used to determine the collagene type. Quantitative analyses of proteins were performed at Qubit fluorometer. Chemiluminescence detection system was performed after 7 minutes of dry bloting. Protein bands were observed between 98 kDa Phosphorylase B-188 kDa myosin.

\section{Statistical Analysis}

Canonical regression analysis with Datafit Version 9.0.59 software package was used for statistical evaluation. The correlations of the content of wells for each plate were calculated.

\section{RESULTS}

Growth of the chondrocytes was observed in flasks with the help of invert microscope (under $x 40$ magnification) taking their microphotographs at every subpassaging (Fig. 2).

\section{Live/Dead Assay}

The increase of the confluent after the 5th passage taken from the osteochondral tissue of primary human 
chondrocytes, grown in colonies and spread on the surface of the flasks was confirmed by the MTS ELISA viability test. The cultured chondrocytes were initially seedeed on "c" wells with a number of $10^{5}$ and concluded with a number of $3,24 \times 10^{6}$ cells. The viability of chondrocytes was measured on calibration curve of the MTS assay and the regression coefficient was calculated as $\mathrm{R}^{2}=0,9422$.

\section{Evaluation of the Hydrogel}

Porous structure of the gel has been investigated by SEM analysis. Pore size of the network was observed under 1.00 KX magnification (10 mm lens opening, WD: $9.0 \mathrm{~mm}$ working range, the voltage application under $10.00 \mathrm{kV}$ EHT) (Fig. 3A), 3.00 KX magnification (10 mm lens opening, WD: $8.5 \mathrm{~mm}$ working range, the voltage application under $10.00 \mathrm{kV}$ EHT) (Fig. 3B), $10.00 \mathrm{KX}$ magnification (1 microM range of the lens, the WD: $9.0 \mathrm{~mm}$ working range, the EHT voltage application under $10.00 \mathrm{kV}$ ) (Fig. 3C), respectively. The sizes of pores were found to be directly proportional to the degree of cross-linking and the porosity percentage was measures as $21 \%$.

\section{Release of GFs}

The determination of the release kinetics of the hydrogels loaded with TGF- $\beta 1$ (a1, a2 and a4wells) and BMP-7 (a1, a3 and a4 wells) was carried out with ELISA for "a" and "c" wells with three repetitions (Fig. 4).

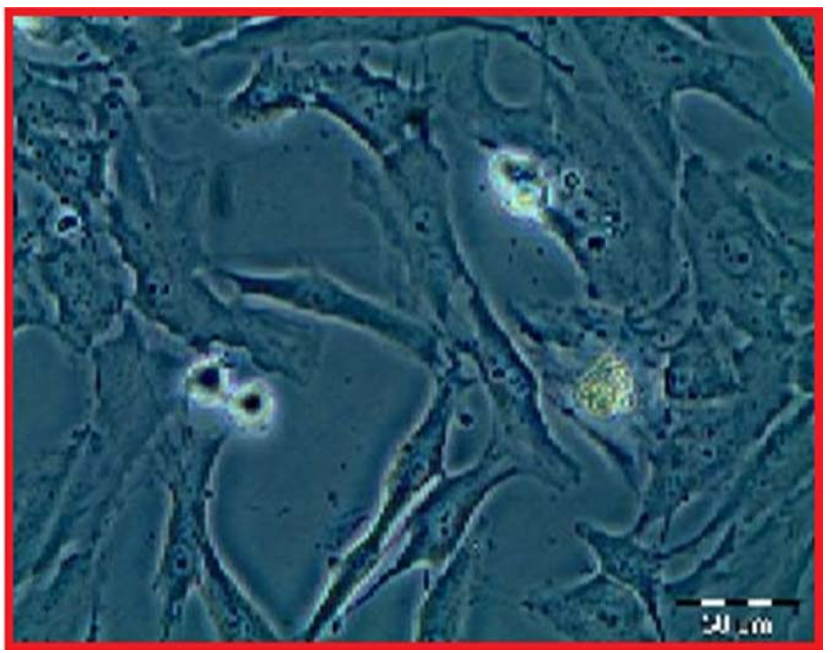

Fig. (2). Growth of the chondrocytes was followed in flasks with invert microscope (under X40 magnification).

Release amounts from well plates, consisted of primary chondrocyte cultures were determined, respectively. High statistical correlation between wells was shown (Table 1).

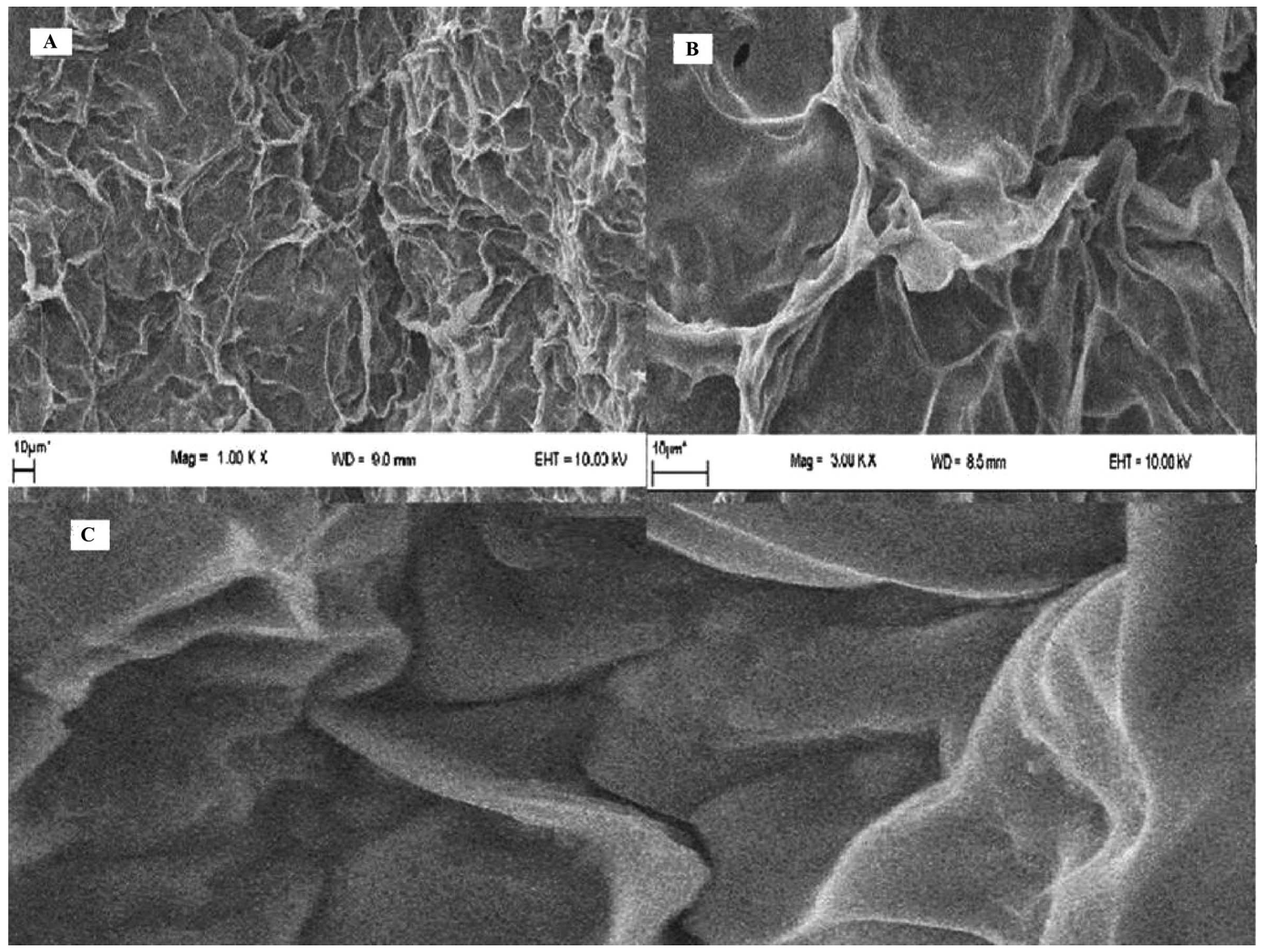

Fig. (3A-C). Hydrogel was evaluated with SEM analysis. The sizes of pores are directly proportional to the degree of cross-linking and the measured porosity percentage was $21 \%$. 

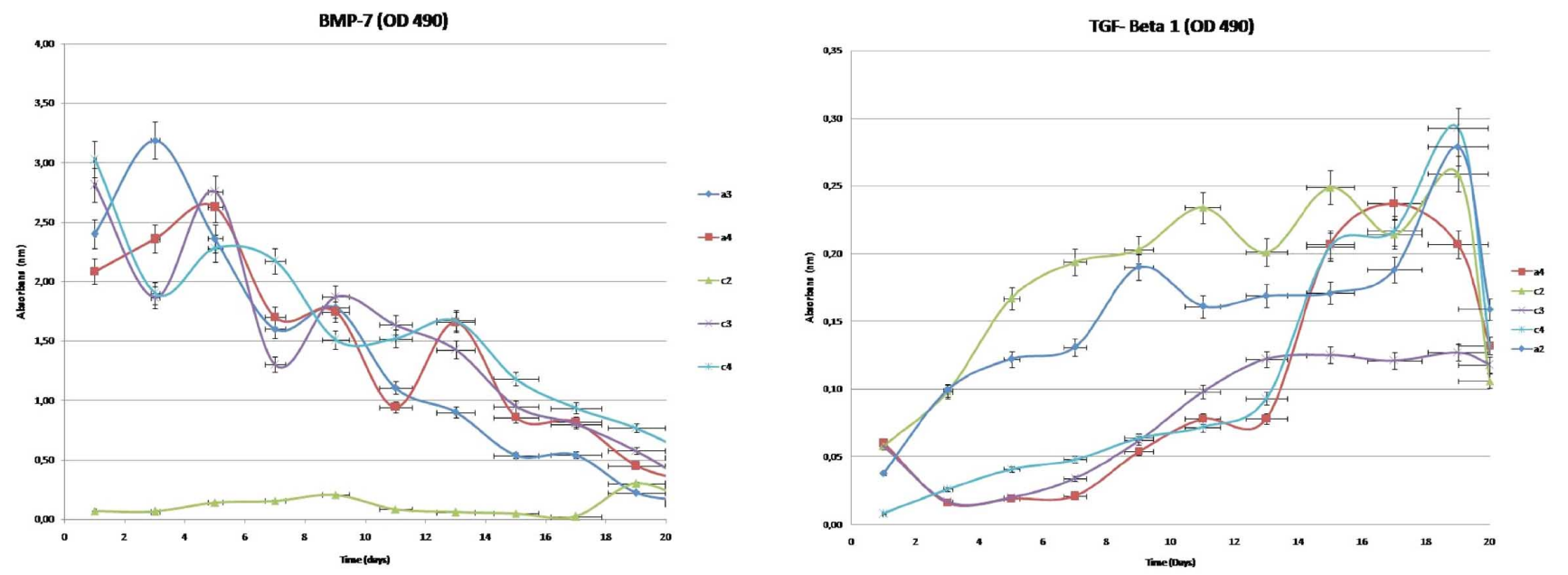

Fig. (4). Controlled release kinetics of TGF-B1 and BMP-7 from hydrogel. Hydrogel of the a2, a4, c2, c3, c4 wells.

Correlation between the groups was also significant (for TGF- $\beta 1, p<0,05$ and for BMP-7, $p<0,001)$. Non- linear formulas, helpful in the calculation of the release amount of TGF- $\beta 1$ and BMP-7 within the wells, have been presented in (Table 1).

Table 1. Regressional Equality Statement for TGF-B1 and BMP-7. Non- Linear Formulas, which may Aid in Calculation of the Release Amount of TGF-p1 and BMP-7 within the Wells, are Presented

\begin{tabular}{|c|c|c|c|c|c|}
\hline $\mathbf{R}^{2}$ & $\mathbf{a 3}$ & $\mathbf{a 4}$ & $\mathbf{c 2}$ & $\mathbf{c 3}$ & $\mathbf{c 4}$ \\
\hline \hline TGF- $\beta 1$ & 0,8075 & 0,9148 & 0,4827 & - & 0,8129 \\
\hline BMP-7 & 0,9083 & 0,8354 & - & 0,8254 & 0,8800 \\
\hline
\end{tabular}

\section{BMP-7 Release Kinetics}

The hydrogel initially loaded with a total of $22,7 \mathrm{ng} / \mathrm{ml}$ BMP-7. BMP-7 release at the a2, a4, c3, c4 wells, in 2-day intervals for 21 days, respectively has been shown in Table 2.

Table 2. BMP-7 Release at the $a_{3}, a_{4}, c_{2}, c_{3}, c_{4}$ Wells, in 2-Day Intervals for 21 Days

\begin{tabular}{|c|c|c|c|c|}
\hline a3 Well & a4 Well & c2 Well & c3 Well & c4 Well \\
\hline \hline $10,5 \%$ & $9.18 \%$ & & $12.39 \%$ & $13.34 \%$ \\
\hline $14.04 \%$ & $10.38 \%$ & & $8.23 \%$ & $8.37 \%$ \\
\hline $10.4 \%$ & $11.57 \%$ & & $12.14 \%$ & $10.03 \%$ \\
\hline $7.1 \%$ & $7.48 \%$ & & $5.73 \%$ & $9.57 \%$ \\
\hline $7.85 \%$ & $7.68 \%$ & & $8.24 \%$ & $6.65 \%$ \\
\hline $4.87 \%$ & $4.2 \%$ & & $7.20 \%$ & $6.69 \%$ \\
\hline $3.96 \%$ & $7.31 \%$ & & $6.29 \%$ & $7.36 \%$ \\
\hline $2.36 \%$ & $3.78 \%$ & & $4.17 \%$ & $5.20 \%$ \\
\hline $2.37 \%$ & $3.60 \%$ & & $3.52 \%$ & $4.12 \%$ \\
\hline $0.98 \%$ & $1.98 \%$ & & $2.53 \%$ & $3.38 \%$ \\
\hline $0.69 \%$ & $1.34 \%$ & & $1.22 \%$ & $2.30 \%$ \\
\hline
\end{tabular}

\section{TGF- $\beta 1$ Release Kinetics}

The hydrogel was initially loaded with a total of $10 \mathrm{ng} / \mathrm{ml}$ TGF- $\beta 1$. TGF- $\beta 1$ release rate at the a2, a4, c2, c4 wells, in 2day intervals for 21 days, respectively has been shown in Table 3.

Table 3. TGF-B1 Release at the $a_{3}, a_{4}, c_{2}, c_{3}, c_{4}$ Wells, in 2-Day Intervals for 21 Days

\begin{tabular}{|c|c|c|c|c|}
\hline a3 Well & a4 Well & c2 Well & c3 Well & c4 Well \\
\hline \hline $0.76 \%$ & $2 \%$ & $1.16 \%$ & & $0.16 \%$ \\
\hline $1.98 \%$ & $0.32 \%$ & $1.96 \%$ & & $0.52 \%$ \\
\hline $2.44 \%$ & $0.38 \%$ & $3.34 \%$ & & $0.82 \%$ \\
\hline $2.62 \%$ & $0.42 \%$ & $3.88 \%$ & & $0.96 \%$ \\
\hline $3.8 \%$ & $1.08 \%$ & $4.06 \%$ & & $1.28 \%$ \\
\hline $3.22 \%$ & $1.56 \%$ & $4.68 \%$ & & $1.44 \%$ \\
\hline $3.38 \%$ & $1.56 \%$ & $4.02 \%$ & & $1.86 \%$ \\
\hline $3.42 \%$ & $4.14 \%$ & $4.98 \%$ & & $4.1 \%$ \\
\hline $3.62 \%$ & $4.74 \%$ & $4.28 \%$ & & $4.34 \%$ \\
\hline $5.58 \%$ & $4.14 \%$ & $5.18 \%$ & & $5.86 \%$ \\
\hline $3.18 \%$ & $2.64 \%$ & $2.12 \%$ & & $2.64 \%$ \\
\hline
\end{tabular}

Combined GFs loaded hydrogel system allowed TGF- $\beta 1$ release after the 9th day (Culture media content $(0.056 \%)$ and the released amounts of the TGF- $\beta 1$ produced by the chondrocytes $(0,92 \%)$ were excluded. $98.34 \%$ of TGF- $\beta 1$ was observed to be released at the end of the 21 st day.

During the first 9 days BMP-7 and consecutively until the 21 st day TGF- $\beta 1$ were released separately from the $\mathrm{c} 4$ well, in therapeutical concentration. The total count of living cells seeded on hydrogels in "c" wells was also assesed with MTS. Significant difference was observed with combined signaling with both GFs.

The total count of living cells seeded on hydrogels in "c" wells was assesed with MTS. Significant difference was observed with combined signaling with both GFs (Fig. 5 and Table 4). 


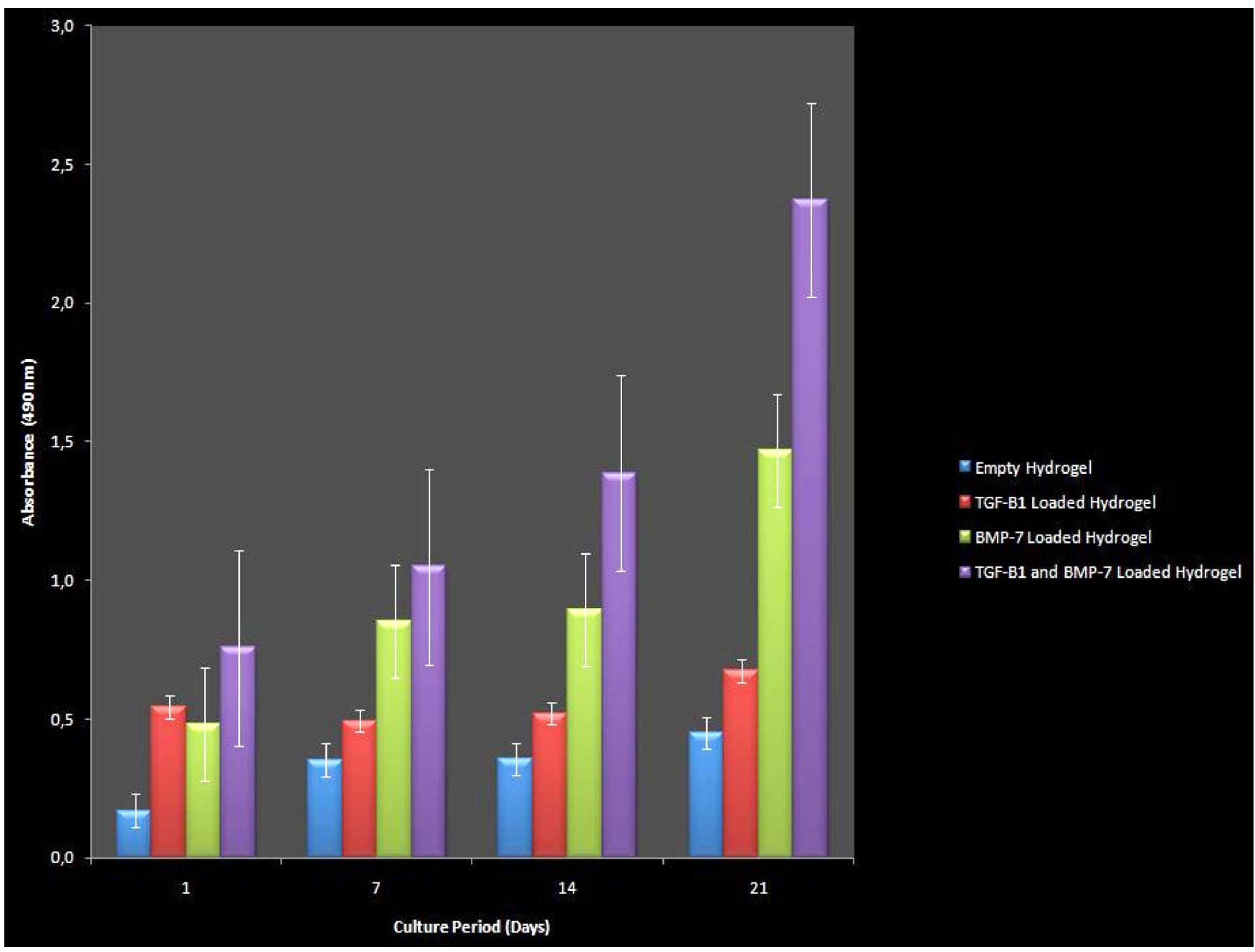

Fig. (5). MTS analysis data of chondrocytes on "c" wells. Western blot analysis showed an increased amount in synthetised collagen types of I and II at $\mathrm{c} 4$ wells. The determined bands and their types were qualified.

Table 4. Cell Counts at Time Interval

\begin{tabular}{|c|c|c|c|c|}
\hline $\begin{array}{c}\text { Chondrocyte } \\
\text { Counts }\end{array}$ & $\begin{array}{c}\text { 1st } \\
\text { Week }\end{array}$ & $\begin{array}{c}\text { 2nd } \\
\text { Week }\end{array}$ & $\begin{array}{c}\text { 3rd } \\
\text { Week }\end{array}$ & $\begin{array}{c}\text { 4th } \\
\text { Week }\end{array}$ \\
\hline \hline Empty Hydrogel & 50 & 750 & 780 & 1,890 \\
\hline TGF $\beta$ 1- loaded & 3,870 & 2,670 & 3,260 & 8,680 \\
\hline BMP7 loaded & 2,470 & 20,840 & 2,4990 & 163,670 \\
\hline Combined & 13,390 & 46,070 & 132,120 & $1,001,670$ \\
\hline
\end{tabular}

Western blot analysis showed an increased amount in synthetised collagen types of I and II at C4 wells qualifying determined bands and their types (Fig. 6).

\section{DISCUSSION}

The controversies in treating the defected cartilage areas of synovial joints with native cartilage still persist, since the majority of treatment algorithyms advise surgeons to implant autologous chondrocytes in larger defects $[2,9,16]$. Recent advances in the field of tissue engineering have enabled the transferring of the cultured chondrocytes with the support of artificial materials called scaffolds [17]. These biomaterials were assigned to facilitate the transfer of the chondrocytes and protect them during the reorganization to host cartilage or chondroneogenesis [18]. GFs have been incorporated into polymer scaffolds in recent studies on cartilage regeneration to sustain the delivery of GFs in vivo and in vitro [19]. The succesfull results are promising for clinical use of the GF enriched scaffolds.

The main limitation of our study was that, in contrast to the literature, cartilage tissue from only one patient was harvested. In order to not confuse the results, all the stages of the current study were conducted thrice. It is believed that for definite conclusions such studies have to be conducted with specimens obtained from identical individuals.

Polymer systems like chitosan based hydrogels have well-known pharmakokinetic mechanisms to control the delivery of the carried GF. Chitosan (=deacetylated chitin) was preferred as the main component of a hydrogel to form a biocompatible, adhesive, surgically applicable, biodegredable, elastic, volumetrically stable and capable to transfer biomaterial with high amount of small size porous matrices $[5,14]$. The velocity released from the polymer was controlled in diffusion mechanism with adjustment of the pore diameters in the way of shrinking with crosslinkers. 


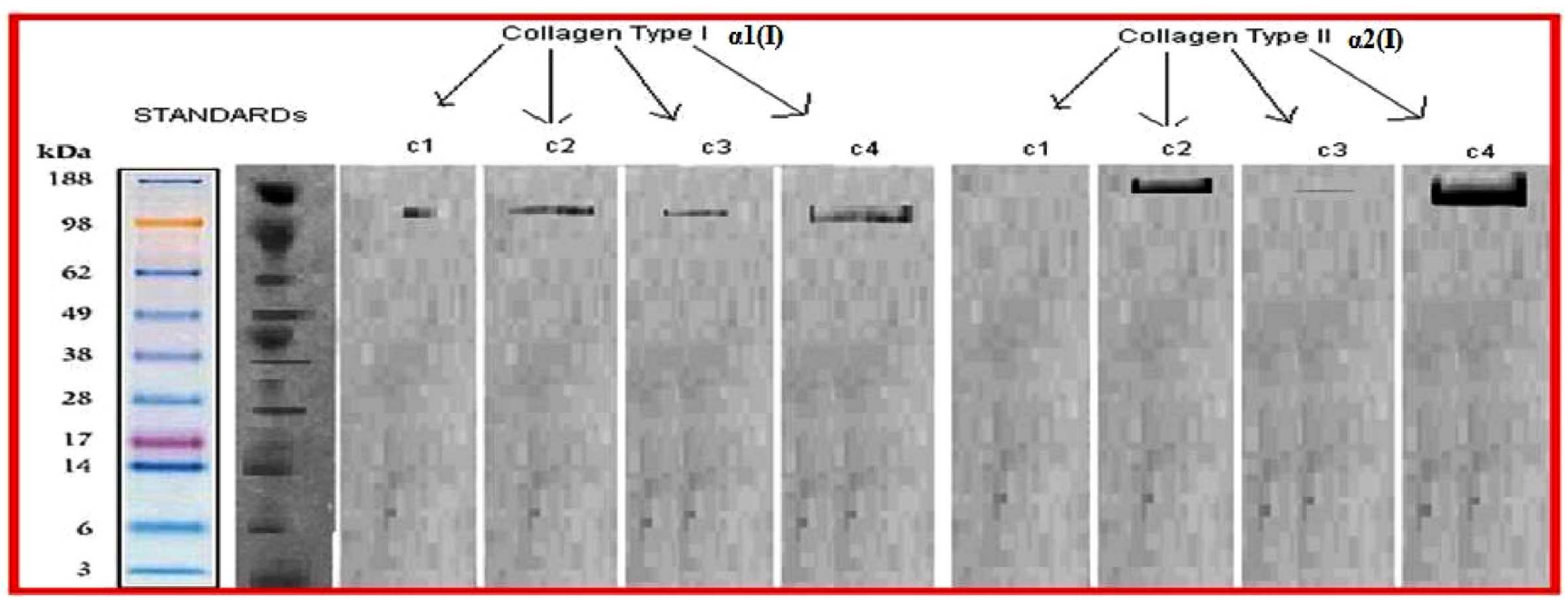

Fig. (6). Western blot analysis showed an increased amount in synthetised collagen types of I and II at C4 wells.

Borax was chosen for crosslinking agent to strengthen the ionic crosslinks. Biodegredation was another mechanism, predicted at our initial swelling tests, which was observed to take part at the surface area of our hydrogel.

Anabolic and stimulating effects of GFs are well known issues in literature $[19,20]$. Both of GF's had previously been investigated due to their different anabolic features. Gavenis et al. found significantly higher content of proteoglycan and collagen type-II protein in the samples cultivated with BMP-7 loaded microspheres in comparison to those of the control samples [21]. Furthermore, their collagen gel scaffold was partially remodeled by the chondrocytes and replaced by newly synthesized extracellular matrix. Stöve et al. also pondered on the stimulating effect of BMP-7 and declared in their study that BMP-7 might be a suitable anabolic activator of osteoarthritic chondrocytes [22]. Incorporation of TGF- $\beta 1$ microspheres into a scaffold [14] and supplementation to a medium [23] was also shown to have the potential to enhance cartilage formation. The effectiveness of a TGF- $\beta 1$ treatment in enhancing chondrogenesis was correlated with its effectiveness in stimulating formation. Excessive amounts and extended treatment periods of TGF- $\beta 1$ were also found in association with osteophyte formation, fibrosis and hypertrophy [24, 25]. We assumed a consecutive release of GFs preventing cartilage tissue from this kind of side effect of TGF- $\beta 1$.

Chubinskaya et al. reported that, GFs, especially combined, promoted cell survival and induced chondrocyte proliferation [26]. A significant promise for anabolic growth factors in cartilage repair as a potential modifying therapy for the enhancement of chondrocytic phenotype of autologous chondrocytes was also suggested.

The combinations of GFs in different studies with carriers were also studied [20]. Among the other varieties of combinations of GFs, the in vitro chondrogenic potential of BMP-7 and TGF- $\beta 1$ was investigated in Nakagawa et al.'s study [27]. The dose and spatial control of GFs disribution and temporal release remained as uncontrolled in the majority of the studies. We expected an augmentation effect in the way of synergism on chondrocytes with sequential delivery of two selected GFs. TGF- $\beta 1$ and BMP-7 both have their action on chondrocytes with signaling their receptors at cellular wall. GFs have an acting pathway through different SMAD subgroups, as an intracellular signaling pathway agent on chondrocyte nucleus. The shared SMAD system may lead to an enhanced growing stimuli on chondrocytes itself and their collagene synthesis. This similarity in intracellular action pathway may be effective in our hypotethic synergism.

There were studies on combined loaded hydrogels, however the idea of changing the release rate or sequential release hydrogels is fairly new [28]. Lim et al. developed a delivery system for dual growth factors using a gelation rate controllable alginate solution containing BMP-7 and polyion complex nanoparticles containing TGF- $\beta 2$ in an application for the chondrogenesis of MSCs [18]. The dual growth factors loaded with nanoparticle/hydrogel system showed a controlled release of both the growth factors: a faster release of BMP-7 and a slower release of TGF- $\beta 2$, approximately $80 \%$ and $30 \%$ release at the end of an incubation period $(21$ days), respectively. To judge the previously shown advantage of early release of BMP-7 followed by TGF- $\beta 1$, a new combined hydrogel was fabricated. According to our hypothesis, the outer layer of hydrogel loaded with BMP-7 was initially biodegradated. BMP-7 was released in early days to the 9th day. Consecutive release of TGF- $\beta 1$ reached its peak concentration at the 15 th day. This pharmaco-kinetic property of hydrogel has affected the grown quantity of cultured chondrocytes and their synthetized collagen amount. This dual layer fabrication method has also allowed a controlled release of a larger amount of loaded GFs contrary to crosslinking and micro/nanospheres.

Extracellular matrix collagene contents were studied in the literature for definition of hyaline cartilage quality. Presence of high concentrated collagen type II was an indicator for hyaline cartilage and stimulation of GF was proven to effect positively on collagene type II synthesis. Claus et al. investigated inducing effect of BMP-2, on chondrocytes immediately after their isolation from cartilage, to maintain their chondrogenic phenotype in longterm culture conditions [29]. They found that, exogeneous BMP-2 dramatically improved the chondrogenic character of 
knee articular chondrocytes amplified over two passages, as assessed by the BMP-2 stimulation on type II procollagen expression and synthesis. Collagen type I and II concentrations were also measured with western blot technique to evaluate and estimated the future behavior of the cultivated chondrocytes and found significantly more concentrations of collagen type II with consecutive GFs used group IV.

\section{CONCLUSION}

Chitosan based hydrogel systems may be adjusted to release GFs consecutively during biodegradation at the layers of surface, which may increase the cell number and enhance collagen type II synthesis. Our results showed that controlled release drug delivery systems are promising with their adjustibility for the release of different peptide contents in different time intervals. Further investigations are needed to find out optimum action time, period and dose interval to promote chondrocytes to form a new cartilagineous tissue.

\section{ACKNOWLEDGEMENT}

Declared none.

\section{CONFLICT OF INTEREST}

The authors confirm that this article content has no conflicts of interest.

\section{REFERENCES}

[1] Lynn AK, Brooks RA, Bonfield W, Rushton N. Repair of defects in articular joints. Prospects for material-based solutions in tissue engineering. J Bone Joint Surg Br 2004; 86(8): 1093-9.

[2] Solchaga LA, Goldberg VM, Caplan AI. Cartilage regeneration using principles of tissue engineering. Clin Orthop Relat Res 2001; (391 Suppl):161-70.

[3] Han SH, Kim YH, Park MS, et al. Histological and biomechanical properties of regenerated articular cartilage using chondrogenic bone marrow stromal cells with a PLGA scaffold in vivo. J Biomed Mater Res A 2008; 87(4): 850-61.

[4] Harris JD, Siston RA, Pan X, Flanigan DC. Autologous chondrocyte implantation: a systematic review. J Bone Joint Surg Am 2010; 92(12): 2220-33.

[5] Hoemann CD, Sun J, Légaré A, McKee MD, Buschmann MD. Tissue engineering of cartilage using an injectable and adhesive chitosan-based cell-delivery vehicle. Osteoarthr Cartil 2005; 13(4): 318-29.

[6] Kerker JT, Leo AJ, Sgaglione NA. Cartilage repair: synthetics and scaffolds: basic science, surgical techniques, and clinical outcomes. Sports Med Arthrosc 2008; 16(4): 208-16.

[7] Zhang Z, McCaffery JM, Spencer RG, Francomano CA. Growth and integration of neocartilage with native cartilage in vitro. J Orthop Res 2005; 23(2): 433-9.

[8] Brandl A, Angele P, Roll C, Prantl L, Kujat R, Kinner B. Influence of the growth factors PDGF-BB, TGF-betal and bFGF on the replicative aging of human articular chondrocytes during in vitro expansion. $\mathrm{J}$ Orthop Res 2010; 28(3): 354-60.

[9] Getgood A, Brooks R, Fortier L, Rushton N. Articular cartilage tissue engineering: today's research, tomorrow's practice? J Bone Joint Surg $\mathrm{Br}$ 2009; 91(5): 565-76.

[10] Wang X, Wenk E, Zhang X, Meinel L, Vunjak-Novakovic G, Kaplan DL. Growth factor gradients via microsphere delivery in biopolymer scaffolds for osteochondral tissue engineering. J Control Release 2009; 134(2): 81-90.
[11] Chuang WY, Young TH, Yao CH. Properties of the poly (vinyl alcohol) / chitosan blend and its effect on the culture of fibroblast in vitro. Biomaterials 1999; 20: 1479-87.

[12] Graeme IH, Dettmar PW, Goddard PA, Hampsor FC, Michael D, Edward JW. The effect of chitin and chitosan on the proliferation of human fibroblasts and keratinocytes in vitro. Biomaterials 2001; 22: 2959-66.

[13] Kim SE, Park JH, Cho YW, et al. Porous chitosan scaffold containing microspheres loaded with transforming growth factor-beta1: implications for cartilage tissue engineering. J Control Release 2003; 91:365-74.

[14] Lee JE, Kim KE, Kwon IC, et al. Effects of the controlled-released TGF-beta 1 from chitosan microspheres on chondrocytes cultured in a collagen/chitosan/glycosaminoglycan scaffold. Biomaterials 2004; 25(18): 4163-73.

[15] Mattioli-Belmonte M, Gigante A, Muzzarelli RA, et al. N,Ndicarboxymethyl chitosan as delivery agent for bone morphogenetic protein in the repair of articular cartilage. Med Biol Eng Comput 1999; 37(1): 130-4.

[16] Magnussen RA, Dunn WR, Carey JL, Spindler KP. Treatment of focal articular cartilage defects in the knee: a systematic review. Clin Orthop Relat Res 2008; 466(4): 952-62.

[17] Nehrer S, Chiari C, Domayer S, Barkay H, Yayon A. Results of chondrocyte implantation with a fibrin-hyaluronan matrix: a preliminary study. Clin Orthop Relat Res 2008; 466(8): 1849-55.

[18] Lim SM, Oh SH, Lee HH, Yuk SH, Im GI, Lee JH. Dual growth factorreleasing nanoparticle/hydrogel system for cartilage tissue engineering. J Mater Sci Mater Med 2010; 21(9): 2593-600.

[19] Zhang Y, Phillips FM, Thonar EJ, et al. Cell therapy using articular chondrocytes overexpressing BMP-7 or BMP-10 in a rabbit disc organ culture model. Spine (Phila Pa 1976) 2008; 33(8): 831-8.

[20] DiCarlo BB, Hu JC, Gross T, Vago R, Athanasiou KA. Biomaterial effects in articular cartilage tissue engineering using polyglycolic acid, a novel marine origin biomaterial, IGF-I, and TGF-beta 1. Proc Inst Mech Eng H 2009; 223(1): 63-73.

[21] Gavénis K, Klee D, Pereira-Paz RM, et al. BMP-7 loaded microspheres as a new delivery system for the cultivation of human chondrocytes in a collagen type-I gel. J Biomed Mater Res B Appl Biomater 2007; 82(2): 275-83.

[22] Stöve J, Schneider-Wald B, Scharf HP, Schwarz ML. Bone morphogenetic protein 7 (bmp-7) stimulates proteoglycan synthesis in human osteoarthritic chondrocytes in vitro. Biomed Pharmacother 2006; 60(10): 639-43.

[23] Emin N, Koç A, Durkut S, Elçin AE, Elçin YM. Engineering of rat articular cartilage on porous sponges: effects of tgf-beta 1 and microgravity bioreactor culture. Artif Cells Blood Substit Immobil Biotechnol 2008; 36(2): 123-37.

[24] Mierisch CM, Cohen SB, Jordan LC, Robertson PG, Balian G, Diduch DR. Transforming growth factor-beta in calcium alginate beads for the treatment of articular cartilage defects in the rabbit. Arthroscopy 2002; 18(8): 892-900.

[25] Nimni ME. Polypeptide growth factors: targeted delivery systems Biomaterials 1997; 18(18): 1201-25.

[26] Chubinskaya S, Hakimiyan AA, Rappoport L, Yanke A, Rueger DC, Cole BJ. Response of human chondrocytes prepared for autologous implantation to growth factors. J Knee Surg 2008;21(3): 192-9.

[27] Nakagawa T, Lee SY, Reddi AH. Induction of chondrogenesis from human embryonic stem cells without embryoid body formation by bone morphogenetic protein 7 and transforming growth factor betal. Arthritis Rheum 2009; 60(12): 3686-92.

[28] Park H, Temenoff JS, Tabata Y, et al. Effect of dual growth factor delivery on chondrogenic differentiation of rabbit marrow mesenchymal stem cells encapsulated in injectable hydrogel composites. J Biomed Mater Res A 2009; 88(4): 889-987.

[29] Claus S, Aubert-Foucher E, Demoor M, et al. Chronic exposure of bone morphogenetic protein-2 favors chondrogenic expression in human articular chondrocytes amplified in monolayer cultures. J Cell Biochem 2010; 111(6): 1642-51. 